\title{
Brief Analysis on O2O Model of Urban and Rural Commerce of Internet plus -Taking Clothing Industry as an Example
}

\author{
Peng Qian \\ Anhui Sanlian University, Hefei 230601, China
}

Keywords: Internet +; O2O; urban-rural; clothing

\begin{abstract}
With the popularity of Internet transactions, the form of network transactions is diversified. Many industries in daily life can be transformed through the "Internet + " model to maximize profits. This paper analyzes the competition phenomenon in the market and clothing industry, and expounds the advantages of the "Internet +" O2O operation mode. Therefore, it is concluded that the use of $\mathrm{O} 2 \mathrm{O}$ management mode in urban and rural clothing stores can improve the current situation, create a new business philosophy, and achieve the goal of win-win.
\end{abstract}

\section{Market Analysis}

With the development of Internet and the rapid rise of e-commerce, online shopping has gradually become a new trend and has become the main way of consumption for young and middle-aged people. Among the urban and rural residents in China, the majority of urban and rural residents are Middle-aged people, the continuous social and economic development, the urban residents and the rural residents' consumption ability have been improved, basically a smart phone, anytime and anywhere can go online shopping. Therefore, the urban and rural physical shops have been greatly affected, or even closed down. All walks of life in the future need to accelerate the pace of transformation, gradually from the traditional mode of operation and sales to the "Internet +" model, that is, the integration of online and offline mode development, on the basis of the entity shop to use the "Internet +" to broaden the network sales channels and to enhance the competitiveness of the market.

\section{Clothing Market Competition and Countermeasures}

\subsection{The competitive clothing industry}

The main characteristics of clothing sales industry are divided into two categories: first, the industry is labor intensive industry, the entrance threshold is low, the technical difficulty and mechanical requirements are not high, and the return cycle of clothing sales is short. Second, new styles are being introduced every season. Fabric and cutting according to technical updates and other uncertain factors fast change, such as: Hot sowing film and television main supporting accessories are sought after, resulting in the clothing industry's product replacement threat.

Therefore, the main competition phenomena in the garment industry are as follows:

- $\quad$ Competition, imitability

- potential competitors

- Substitute product threat

\subsection{Main countermeasures}

- We should step up publicity efforts to improve service quality, retain old customers and develop new customers.

- Continue to conduct market research, identify service types, and constantly seek personalized products, in order to seek more market.

- $\quad$ Seek service innovation and use alternative innovative thinking to serve enterprises. 


\section{3. "Internet +" O2O Operation Mode}

Through the analysis of the market and the clothing market, it is concluded that the "Internet +" O2O operation mode in urban and rural clothing stores is an innovative marketing thinking model. O2O operation mode refers to combining the business opportunities under the line with the Internet, making the Internet a platform for offline transactions, that is, using the "Internet + " innovation model. "Internet + " popularly says, "Internet + each traditional industry". Most of the customer groups in China's urban and rural clothing shops are above young and middle-aged people. The consumption pattern is mainly physical stores, followed by online shopping. With the popularity and application of the Internet and smart phones, the trend of online shopping by urban and rural residents is increasing year by year. If urban and rural clothing stores still adopt the traditional business model, then the other $\mathrm{O} 2 \mathrm{O}$ clothing stores will be squeezed out of the market in the near future.

\section{The Superiority of O2O Model}

O2O's perfect combination of online and offline is its biggest advantage. The main manifestation is: the price is cheap, the purchase is convenient, and the discount information can be learned in time, so that the consumer can enjoy the high quality service under the line while enjoying the online preferential price. In addition, $\mathrm{O} 2 \mathrm{O}$ mode can also achieve different business alliances.

In fact, for the clothing industry, to truly realize the "Internet +" O2O operation mode, life experience shop is the most ideal way. The so-called life experience shop model is different from the traditional entity store. The life experience store provides some life services for the customers on the basis of the entity store, such as dessert, fruit, fashion magazine, leisure area, children's paradise and so on. The time for choosing and trying to wear clothes is more abundant, thus prolonging the time of customers staying in the store. Customers can directly place orders online after trying on them. In addition, later customers know the brand style, style, size and other information on the Internet. Even if they don't get to the life experience store, they can buy them online directly, which can attract more customers. Therefore, this mode is the real O2O mode of online sales and offline experience.

Therefore, the urban and rural clothing stores want to quickly sound the brand and occupy the market to expand the operating income. The operation mode of $\mathrm{O} 2 \mathrm{O}$ is the most ideal mode of operation, which can be realized through the following ways:

- The combination of entity stores and online stores will expand sales.

- $\quad$ Ensure the quality of garments on the basis of price concessions.

- Catch the old customers and attract more new customers through the O2O operation mode.

- Catch the old customers and attract more new customers through the O2O operation mode.

- $\quad$ Provide quality service in O2O mode, form its own brand effect, expand business scope and entity chain store.

\section{References}

[1] Peiqiang Li. Electronic commerce [M]. Shanghai: Shanghai Jiao Tong University press, 2015.9

[2] Chong Guo. Analysis of the impact of the development of "Internet + " on the consumption of urban and rural residents in China [J]. Commercial economic research, 2017 (20): 41-43

[3] How does the clothing industry realize the true meaning of O2O? http://news.163.com/16/1025/11/C47JQQK400014AEE.html 